\title{
A NOVA CONCEPÇÃO CONTRATUAL COM BASE NO CÓDIGO DE DEFESA DO CONSUMIDOR E A ALIENAÇÃO FIDUCIÁRIA
}

Danielli Borin Menezes ${ }^{1}$

\begin{abstract}
Resumo: Aborda uma visão geral da nova concepção contratual a partir do Código de Defesa do Consumidor, através de uma análise histórica e do resgate de alguns valores importantes como a boa-fé e como são tratados os contratos de adesão nesse contexto. Além disso, traz observações sobre o instituto da alienação fiduciária, as regulamentações e a sua conexão com a nova concepção contratual.

Palavras-chave: Código de Defesa do Consumidor - contrato de adesão - alienação fiduciária.
\end{abstract}

The new conception contractual with base in Costumer's Defense Code and the alienação fiduciária

\begin{abstract}
It approaches a general vision of the new contractual conception from the Consumer's Defense Code, through one history analisis and the rescue of some important good faith values and how the contracts of support in this context are trated. Besides this, bring observations about institute of alienação fiduciária, the regulations and the connection of the new contractual conception.

Key-words: Consumer's Defense Code - standard contracts - alienação fiduciária.
\end{abstract}

\section{INTRODUÇÃO}

Este trabalho tem por objetivo tecer comentários sobre o instituto da alienação fiduciária à luz do CDC e tendo por base um dos contratos mais importantes na modernidade, o contrato de adesão.

Trata da evolução em matéria de contratos, desde o princípio da pacta sunt servanda, da defesa da autonomia da vontade e da liberdade contratual, até a defesa dos interesses do contratante mais fraco pelo Estado Social, tendo como maior aliado o Código de Defesa do Consumidor. Além desses aspectos, faz-se referência à nova concepção de contrato que surgiu com o advento de tal código que leva em conta não mais a liberdade entre as partes, mas sim, a equidade que deve haver entre elas. Ademais, frente a tais transformações, observa-se o comportamento da alienação fiduciária e as conceituações e divergências existentes nesse instituto muito usado modernamente.

\footnotetext{
${ }^{1}$ Acadêmica do $5^{\circ}$ semestre de Direito da UFSM, período diurno. E-mail: danielimenezes@ yahoo.com.br.

ISSN - 1981-3694

(C) 2007. Departamento de Direito da UFSM. Todos os direitos reservados.
} 
Para fazer tal análise utilizou-se de equiparações e entrelaçamentos entre os institutos a fim de obter uma explanação mais concisa e objetiva, tendo em vista a ressalva dos principais aspectos da matéria. Dessa forma, o presente trabalho vem dividido em duas partes principais, a primeira onde serão feitas explanações sobre os direitos do consumidor e as relações consumeiristas, além de fazer alusão aos contratos de adesão que estão intimamente ligados a tais relações e a segunda parte, onde serão expostas algumas considerações sobre o instituto da alienação fiduciária, seu conceito e a sua conexão com a primeira parte.

\section{CONTRATO DE ADESÃO E O CÓDIGO DE DEFESA DO CONSUMIDOR}

Para que se tenha uma breve noção da importância que o Código de Defesa do Consumidor passou a ter ao longo do tempo, é necessário que se faça uma análise histórica de evolução das relações contratuais, bem como, as consumeiristas, visando com isso entender o surgimento da nova concepção contratual e a sua importância na atualidade.

\subsection{Evolução Histórica das relações consumeiristas e dos contratos de adesão.}

A Teoria Geral dos Contratos teve o seu ápice de dogmatização a partir do liberalismo, passando, o contrato, a partir deste momento histórico, a ser o negócio jurídico mais importante celebrado entre as pessoas. Como reflexo do Estado liberal, pôde-se notar um crescente apego às ideologias da igualdade e liberdade entre as pessoas, o que, conseqüentemente, passou a influir na maneira de contratar. Mas, posteriormente, o avanço industrial e tecnológico veio a demonstrar que a liberdade contratual não passava de uma ficção frente ao grande desequilíbrio econômico entre as partes. Passou-se a ver que a igualdade entre os homens na sociedade era uma fantasia, que o que se mostrava na realidade era uma grande discrepância entre todos e, em especial, entre as partes contratantes.

No final do século XIX, início do século XX, começou a ser discutida uma nova concepção no direito dos contratos, uma concepção social. Além da manifestação da vontade, também passaram a ser levados em conta os efeitos sociais do contrato e as condições econômicas das partes que o celebravam. E, foi na busca de um maior equilíbrio 
contratual, que posteriormente as legislações passaram a proteger tais interesses sociais, norteando-se em novos princípios que foram surgindo com o decorrer dos tempos, tais como o Princípio da Boa-Fé, valorizando, dessa forma, a confiança depositada no vínculo contratual, como expõe Cláudia Lima Marques (2006, p.210).

Foi nesse contexto, que, em 1990, foi promulgado no Brasil o Código de Defesa do Consumidor (CDC), que veio dar superioridade à vontade social, intervindo nas relações contratuais de modo a assegurar aos consumidores uma maior valorização dos seus interesses e primando pelo equilíbrio entre as partes.

Com o passar do tempo, os contratos de consumo passaram a ser feitos para grandes massas, visto o aumento da oferta e da procura por tais serviços, gerando com isso um aumento no número de cláusulas abusivas que passaram a aprisionar a parte mais fraca da relação. Estava-se diante dos "contratos de adesão", que desde seu surgimento, só tiveram uma utilização cada vez mais crescente em meio às relações consumeiristas.

Essa modalidade contratual, bem como evidencia Arnaldo Rizzardo (2005, p.99), possui características bastante peculiares que a diferencia dos outros tipos de contratos bilaterais geralmente utilizados. Dentre elas, podemos destacar como as mais elencadas entre a doutrina a sua uniformidade, visto que com ele pretende-se obter um grande número de aderentes que aceitem passivamente as mesmas condições; a sua rigidez, justamente por ele ter que ser uniforme, não poderem as partes que o vão aceitar discutir as suas cláusulas; e por fim, a sua predeterminação, visto que suas cláusulas são predeterminadas por uma das partes, o que caracteriza a oferta de um contrato de adesão já como um contrato potencial, obra exclusiva de uma das partes.

A coletividade a que ele é oferecido não possui outra opção senão contratar dessa forma, pois, geralmente tais contratos versam sobre atividades necessárias a todos nos tempos atuais, as quais não se podem abrir mão. Daí que a parte eminentemente mais fraca está condicionada a ligar-se à parte economicamente mais forte, por contingências próprias da estrutura social (RIZZARDO, 2005).

Em virtude dos muitos abusos ocorridos com a utilização desse tipo contratual, o CDC, em seu artigo $54^{2}$, define alguns limites que devem ser respeitados pelas partes,

\footnotetext{
${ }^{2}$ Estabelece o artigo 54 do CDC que os contratos de adesão devem ser redigidos de forma clara e com caracteres ostensivos e legíveis de modo a facilitar sua compreensão pelo consumidor e
} 
principalmente a parte que o oferta, pois o abuso que se mostra nesses contratos ocorre, muitas vezes, porque o consumidor é obrigado a aderir a textos pré-formulados, cuja redação não poderá modificar, o que mostra claramente a desigualdade entre as partes contratantes. O CDC veio, dessa forma, defender os interesses da parte que se apresenta hipossuficiente na relação, assegurando, assim, o respeito a princípios elementares que devem ser seguidos na contratação.

\subsection{A nova concepção contratual (CDC)}

Com a nova visão contratual tem-se uma relativização do princípio da pacta sunt servanda ${ }^{3}$ e também da liberdade contratual. Os fundamentos que regiam os contratos baseados na igualdade entre as partes e a sua livre iniciativa e escolha ficaram ultrapassados à medida que cada vez mais a modernidade impunha limites a tais preceitos. Os contratos de adesão são os principais exemplos de tais limitações, pois é através deles que a grande maioria das pessoas contrata para obter serviços básicos e de primeira necessidade em suas vidas, como o fornecimento de água, energia, transporte entre outros. Os contratos assim redigidos não têm a intenção de manter uma igualdade entre os contratantes, ao contrário, eles visam reforçar a superioridade econômica e jurídica do fornecedor, já que é ele quem formula previamente as cláusulas que deverão ser aceitas pela parte mais fraca.

Baseado nessas mudanças, o CDC veio a regular tais relações e tentar impedir que ocorram abusos por parte de quem produz os contratos. Trouxe, o CDC, uma nova concepção contratual, uma concepção social, que leva em conta não só o momento da contratação, mas também os efeitos que tal ato terá na sociedade. O Estado Social passa a ser mais presente nessas relações e a interferir em favor da parte mais fraca, assim como preceitua Cláudia Lima Marques (2006, p.211):

Haverá um intervencionismo cada vez maior do Estado nas relações contratuais, no intuito de relativizar o antigo dogma da autonomia da vontade com as novas preocupações de ordem social, com a imposição de um novo paradigma, o princípio da boa-fé objetiva. É o contrato, como instrumento à disposição dos

também que as cláusulas que implicarem limitações aos direitos do consumidor deverão ser redigidas com destaque para que permitam seu imediato e fácil entendimento.

${ }^{3}$ O princípio da pacta sunt servanda afirma que os contratos existem para serem cumpridos, é o princípio da força obrigatória, segundo o qual o contrato faz lei entre as partes.Preserva a autonomia da vontade e a liberdade de contratar. 
indivíduos na sociedade de consumo, mas, assim como o direito de propriedade, agora limitado e eficazmente regulado para que alcance a sua função social.

Nesse contexto, um contrato bastante mencionado pelo doutrina é o da alienação fiduciária. Essa espécie contratual caracteriza-se por ser acessória e geralmente se ligar a um contrato que é por excelência da sociedade de consumo: o contrato de compra e venda.

Nos dias atuais, muito se utiliza a compra e venda com alienação fiduciária principalmente para se adquirir bens duráveis e de grande valor e é por tal razão, em virtude da relação consumeirista que ela cria, é que se passou a considerá-la como um contrato de consumo por natureza, logo submetido ao CDC.

\section{ALIENAÇÃO FIDUCIÁRIA EM GARANTIA}

A alienação fiduciária em garantia é uma espécie do gênero alienação fiduciária. A palavra fidúcia significa antes de tudo o negócio e é através desse negócio que se dá a transferência, a translação de titularidade da coisa, transmite-se a plena titularidade do direito (RIZARDO, 2005).

\subsection{Conceituação e Legislação.}

A fidúcia pode ser entendida como um acordo de boa-fé pelo qual uma pessoa, chamada fiduciária, recebe de outra, o fiduciante, um bem mediante uma venda. Quem recebe a coisa se compromete a dar-lhe uma destinação própria e a restituí-la quando for exigida. Dá-se a idéia de transferência da coisa, transmite-se a plena titularidade do direito. Trata-se de um contrato pelo qual o fiduciário adquire aparentemente um bem e obriga-se a restituí-lo ao alienante depois de encerradas as causas que motivaram a venda. ${ }^{4}$

A alienação fiduciária em garantia consiste em uma transferência de propriedade, porém não com o fim de troca, mas com o fim de garantia, para que o bem transmitido

\footnotetext{
${ }^{4}$ Trata-se de negócio jurídico autônomo, da espécie dos negócios de garantia, com traços originais, sem embargo de ser tido como especial modalidade de negócio fiduciário (GOMES, 1997, p.459).
} 
garanta ao fiduciário que ele irá receber o que é seu por direito, o pagamento da dívida que o fiduciante possui com ele; o outro retém a posse sob condição resolutiva da dívida ser saldada, destina-se a garantir a dívida do devedor em favor do credor ${ }^{5}$. É indispensável, para que isto ocorra, que haja confiança entre as partes, sendo que só através dela é que se conseguirá atingir os resultados esperados.

Consiste, dessa forma, em um contrato acessório, que depende de um outro contrato celebrado pelo devedor em relação ao credor. Quando o contrato principal for cumprido, o bem retorna à posse do devedor, podendo este fazer um exercício regular do seu domínio.

A alienação fiduciária em garantia veio a ser regulada no ordenamento brasileiro pela Lei $\mathrm{n}^{\circ} 4.728 / 65$, que disciplinava o mercado de capitais e logo após pelo Decreto-lei $\mathrm{n}^{\circ}$ 911/69 ${ }^{6}$ que passou então a regrar tais contratos, juntamente com a Lei $n^{\circ} 10.931 / 2004$, que modificou, em parte, o decreto. No Código Civil, o assunto é tratado nos artigos 1.361 a 1.368 .

Como afirma Fábio Ulhoa Coelho (2006, p.461), a alienação fiduciária em garantia pode ter por objeto bem já pertencente ao devedor e é nesse sentido que o STJ sumulou em 1991, segundo a súmula 28 do STJ, “o contrato de alienação fiduciária em garantia pode ter por objeto bem que já integrava o patrimônio do devedor", podendo tal objeto ser bem móvel ou imóvel, sendo no caso o último aplicável a Lei $n^{\circ}$ 9.514/97, que instituiu o sistema de financiamento imobiliário. Mas, sua larga utilização está no campo do financiamento de bens de consumo duráveis, sendo, atualmente, um dos principais objetivos do negócio fiduciário: garantir as operações de crédito para a aquisição de utilidades móveis. Desta forma, pode-se observar que se trata de uma relação de consumo, sendo, dessa forma, regida pelo CDC.

\subsection{Alienação fiduciária e a sua relação com a nova concepção contratual.}

\footnotetext{
${ }^{5}$ De acordo com Pontes de Miranda, sempre que a transmissão tenha um fim que não seja a transmissão mesma, de modo que ela sirva a negócio jurídico que não venha a ser de alienação àquele a quem se transmite, diz-se que há fidúcia, ou negócio fiduciário (MIRANDA, 1954, apud, RIZZARDO, 2005, p.1296).

${ }^{6}$ Estabelece o art. 1ํ do Decreto-lei 911/69: “A alienação fiduciária em garantia transfere ao credor o domínio resolúvel e a posse indireta da coisa móvel alienada, independentemente da tradição, efetiva do bem, tornando-se o alienante ou devedor em possuidor direto e depositário com todas as responsabilidades e encargos que the incumbem de acordo com a lei civil e penal”.
} 
Como visto anteriormente, a alienação fiduciária possui natureza meramente instrumental, ou seja, constitui um meio de garantia para o credor e uma forma de facilitar que o devedor alcance o que almeja. É um contrato ou negócio em que se transmite uma coisa ou um direito a outrem, para determinado fim assumindo, assim, o adquirente a obrigação de usar da coisa ou do direito e, uma vez satisfeito o mesmo, de devolvê-lo a quem os transmitiu (RIZZARDO, 2005). O $\S 3^{\circ}$ do artigo 1.361 preleciona o retorno da propriedade ao devedor: "A propriedade superveniente, adquirida pelo devedor, torna eficaz, desde o arquivamento, a transferência da propriedade fiduciária”.

Seu fator de distinção dos outros institutos está justamente no fim fiducial, se cumprido o pagamento, o devedor terá de volta o seu bem que foi dado em garantia, caso contrário, o credor fica autorizado a vender o bem e aplicar o resultado da venda no pagamento do seu crédito, a menos que haja questões pendentes, como, por exemplo, estar o consumidor discutindo no judiciário, alguma cláusula que tenha considerado abusiva. ${ }^{7}$ Enquanto houver alguma pendência, não pode o fornecedor se desfazer do bem, caso este esteja em sua posse.

Nesse contexto, temos como uma das principais formas de utilização da alienação fiduciária, quando usada conjuntamente ao contrato de compra e venda, que constitui um dos institutos onde é mais evidenciada a relação de consumo.

$\mathrm{Na}$ compra e venda geralmente estão bem explícitas as figuras do fornecedor e do consumidor. Nela verifica-se a transferência de domínio de um bem ou de algum direito. Para Orlando Gomes (1997, p.244): “Compra e venda é o contrato pelo qual uma das partes se obriga a transferir a propriedade de uma coisa à outra, recebendo em contraprestação determinada soma de dinheiro ou valor fiduciário equivalente”. Por ser uma relação de consumo, vem a ser regulada pelo $\mathrm{CDC}$, ficando, portanto, protegido legalmente o consumidor contra os abusos que o fornecedor possa vir a lhe submeter.

É nesse ínterim que se encontra a alienação fiduciária. Por ser um instituto baseado na confiança e na transferência de bens ou direitos, quando associada à compra e venda, dá ao fornecedor maiores garantias de que seu crédito será satisfeito. O consumidor comum, ao realizar uma compra e venda a prestações, em um financiamento, por exemplo, está

\footnotetext{
${ }^{7}$ Nesse sentido, decisão do TJ/RS, Apelação Cível 70019009273, j. 10.05.2007, Des. Dorval Bráulio Marques.
} 
fazendo parte de uma relação triangular, que se apresenta de forma mais complexa, por isso a necessidade da garantia dada em troca. A pessoa que decide contratar, o consumidor, no caso, que deseja realizar uma compra, oferece ao fornecedor do produto ou serviço algum bem ou direito que possa dar a ele garantia de que as prestações que ele estará assumindo na compra serão adimplidas corretamente, dando ao fornecedor o direito de dispor de tal garantia em caso de inadimplemento.

Nessas relações, é de primordial importância o respeito a princípios elementares como o da boa-fé para que não ocorram abusos e para que ao final, com o contrato cumprido, possa o consumidor reaver seu bem ou direito dado em garantia sem nenhum prejuízo, sem cobranças excessivas ou até mesmo a inserção do seu nome no cadastro de inadimplentes de forma irregular ${ }^{8}$.

Neste sentido, encontram-se diversas decisões jurisprudenciais do Tribunal de Justiça do Rio Grande do Sul, especialmente no sentido de proteção e defesa dos direitos do consumidor no que diz respeito a taxas de juros elevadas e cobranças abusivas por parte do fornecedor do crédito ${ }^{9}$. Mas, por outro lado, o Superior Tribunal de Justiça apresenta alguns entendimentos diversos, que privilegiam os fornecedores e respaldam contratos que por vezes podem se tornar bastantes onerosos para o consumidor. Em decisão recente, tem admitido, o STJ, a não limitação da taxa de juros remuneratórios em 12\%, além da cobrança da comissão de permanência, situações que privilegiam a ordem econômica e estão flagrantemente em descompasso com o $\mathrm{CDC}^{10}$. Entretanto, embora haja tais entendimentos, a maioria dos julgadores tem primado pela defesa dos interesses do consumidor, pois são eles que geralmente se apresentam na relação contratual como a parte em grande desvantagem, muitas vezes por apresentarem os contratos essas estipulações que quase sempre são unilaterais e largamente abusivas.

Portanto, a aplicação do Código de Defesa do Consumidor em tais situações veio para superar alguns entraves de legislação, além de dar maior segurança aos contratantes, por ser um diploma legal confiável e novo, com uma concepção de equitatividade. Já existe farta jurisprudência sobre a alienação fiduciária, o CDC e as leis especiais, por exemplo,

\footnotetext{
${ }^{8}$ Nesse sentido, decisão do TJ/RS, Agravo de Instrumento 70020420741, j. 03.07.2007, Des. Sejalmo Sebastião de Paula Nery.

${ }^{9}$ Nesse sentido, decisão do TJ/RS, Apelação Cível 70010240000, j. 29.09.2005, Desa. Lúcia de Castro Boller.

${ }^{10}$ Nesse sentido, decisão do STJ, Resp 894385/RS, j.27.03.2007, Min. Nancy Andrighi.
} 
que aplicam o CDC, suas cláusulas gerais, lista de cláusulas abusivas e facilidades processuais e que recusam a perda das prestações já pagas, como regula o seu artigo 53 e a venda do bem dado em garantia sem a inadimplência do consumidor. São fatores como esses que fazem com que o CDC seja de grande importância na alienação fiduciária, visto que, sua aplicação de forma correta, como está sendo feita na maioria dos casos, evita que ocorram abusos que eram tão freqüentes antes da sua existência.

\section{CONSIDERAÇÕES FINAIS}

Dessa forma, pôde-se observar a evolução ocorrida nas relações de consumo ao longo dos anos e especialmente com o advento do Código de Defesa do Consumidor e a limitação da liberdade das partes em contratar com a inserção cada vez maior dos contratos de adesão.

Passou-se a dar mais importância à equidade que deve haver entre as partes e com isso começou-se uma defesa cada vez maior da parte que se apresenta hipossuficiente nas relações.

Através da análise da alienação fiduciária em garantia pôde-se extrair a idéia de como é importante o respeito aos princípios elementares, especialmente nesse caso o da boa-fé, para que os contratos possam atingir seus objetivos, visto que tal modalidade fundase na confiança existente entre as partes.

Além disso, observou-se a influência que o CDC apresenta em tal instituto, como rege as relações consumeiristas que se fundam na confiança, especialmente através do contrato de compra e venda, sempre buscando manter a equidade entre as partes contratantes e tentando-se evitar que ocorram abusos por parte do fornecedor, que geralmente é a parte mais forte do contrato.

A nova concepção contratual, consagrada com o advento do Código de Defesa do Consumidor, veio para tornar mais justas as relações contratuais, mesmo nos casos dos contratos de adesão, fazendo com que se aumente o grau de segurança e respeitabilidade entre os contratantes, seja quando utilizam-se da alienação fiduciária, ou qualquer outro instituto jurídico que é por ele regulado. 


\section{REFERÊNCIAS BIBLIOGRÁFICAS}

ALVES, José Carlos Moreira. Da alienação fiduciária em garantia. Rio de Janeiro: Forense, 1987.

BRASIL. Constituiçãa Federal, Código Civil, Código de Processo Civil/ organizador Yussef Said Cahali. $7^{\mathrm{a}}$ ed. atual. e ampl. São Paulo: Editora Revista dos Tribunais, 2005.

COELHO, Fábio Ulhoa. Manual de Direito Comercial. São Paulo: Saraiva, 2006.

CUNHA, Belinda Pereira da e Bartechiuvi, Mário. A alienação fiduciária em garantia à luz das disposições do Código de Defesa do Consumidor. Disponívelem: $<$ http://www.gentevidaeconsumo.org.br/dir_consumidor/belind a/alienacao_fiduciaria.htm $>$. Gente, vida e consumo. Acesso em: 20 fev. 2007.

FORGIARINI, Giorgio. Aspectos relevantes da alienação fiduciária em garantia. Disponível em: http://jus2.uol.com.br/doutrina/texto.asp?id=3108. Jus Navigandi. Acesso em: 20 fev. 2007.

GOMES, Orlando. Contratos. Rio de Janeiro: Forense, 1997.

GRINOVER, Ada Pellegrini...[et al.]. Código Brasileiro de Defesa do Consumidor. Rio de Janeiro: Forense Universitária, 1998.

MARQUES, Cláudia Lima. Contratos no Código de Defesa do Consumidor: o novo regime das relações contratuais $-5^{\text {a }}$ ed. São Paulo: Editora Revista $\operatorname{dos}$ Tribunais, 2006.

RIZZARDO, Arnaldo. Contratos. Rio de Janeiro: Forense, 2005. 